\title{
DEPRESSION IN SPINAL CORD INJURED PATIENTS
}

\author{
By Timothy Howell, ${ }^{1}$ M.D., Donald T. Fullerton, ${ }^{1}$ M.D. \\ Richard F. Harvey, ${ }^{1}$ M.D. ${ }^{2}$ and Marjorie Klein, ${ }^{1}$ Ph.D. ${ }^{1}$ \\ 1 University of Wisconsin Hospital, Department of Psychiatry, 600 Highland Avenue, \\ Madison, Wisconsin, 53792, U.S.A.; ${ }^{2}$ University of Wisconsin Hospital, Department of \\ Rehabilitation Medicine, 600 Highland Avenue, Madison, Wisconsin, 53792, U.S.A.
}

\begin{abstract}
Many regard depression as an inevitable psychological sequela of spinal cord injury. This assumption, if inaccurate, may confound the rehabilitation process. We evaluated 22 patients with recent spinal cord injuries (less than 6 months), using a standardised interview and diagnostic process. Five patients ( 22 per cent) had diagnosable depressions after their injury. This is higher than the incidence of depression in the general population, but less than anticipated.
\end{abstract}

Key words: Spinal cord injury; Depression.

\section{Introduction}

DEPRESSIONS have the potential to affect adversely the rehabilitation of patients with spinal cord injury. It is commonly assumed that most patients with traumatic paraplegia or tetraplegia eventually develop depressions following their injuries (Wittkower, 1954; Stewart, 1977a; Bracken, 1980). Depression is sometimes described as a stage in a series of reactions that these patients must go through in response to their injuries (Hohmann, I975; Stewart, I977b; Bracken, I980). One researcher has even claimed that those spinal cord injured patients not manifesting any signs or symptoms of depression are nonetheless actually depressed, but masking the dysphoria through denial (Siller, I969). If unwarranted, such assumptions might have significant countertherapeutic effects on rehabilitation. Only recently have such assumptions begun to be questioned (Cook, I976; Trieschmann, I980). A review of the literature reveals collections of clinical impressions or theoretical discussions about depression in spinal cord injury patients, and little in the way of reliable clinical diagnostic criteria. In this study we used the Schedule for Affective Disorders and Schizophrenia (SADS) and the Research Diagnostic Criteria (RDC) to determine the presence or absence of depression or other mental disorders in a population of spinal cord injury patients. We report the results from the first year of investigation.

\section{Method}

The University of Wisconsin Hospital is a centre for spinal cord injury patients, receiving them directly, or by referral, from Wisconsin and northern Illinois. All patients entering the rehabilitation ward with a spinal cord injury sustained in the previous 6 months, who did not have a severe head injury, were asked to take part in the study. All interviews and ratings were done by psychiatrists who were not part of the rehabilitation staff and who did not otherwise have contact with the patients. Each patient was interviewed within one week of arrival in the rehabilitation ward, utilising the Schedule for Affective Disorders 
and Schizophrenia (Lifetime Version) (SADS-L) (Endicott, I978; Spitzer, I978a), and diagnosed according to RDC (Spitzer, I978b and I978c). The SADS is a standardised interview schedule which was designed to detect the presence of affective disorders. The RDC is a reliable and standardised diagnostic protocol which utilises well-defined, specific diagnostic criteria. The Research Diagnostic Criteria define a depressive disorder as sustained and pervasive dysphoric mood accompanied by biological (vegetative), behavioural, and cognitive symptoms. Depressed affect, which is neither pervasive nor prolonged, does not qualify for diagnosis.

Each patient also completed the Beck Depression Inventory (Beck, I96I). After the initial interview, the patients completed the Beck questionnaire at weekly intervals. Those with follow-up Beck scores of 13 or higher were re-evaluated for depression with a structured interview in which an abbreviated version of the SADS, the SADS-C (Change Version) (Spitzer, I978a) was employed.

\section{Results}

Twenty-six patients were approached: 22 gave their informed consent and took part in the study, while four others declined to participate (while we were unable to include these patients in our study, it was our clinical impression that none of them were depressed). The patients ranged in age 16 to 56 (mean $=22 \cdot 7$ ). Nineteen were male and three were female. Fifteen were single, six were married, and one was divorced. In every case the cause of injury was trauma: motor vehicle accident (8), diving accident (5), fall (4), motorcycle accident (2), crushed by a falling object (2) and airplane crash (I). Ten were quadriplegic and 12 were tetraplegic. The time from the accident causing the injury to the initial evaluation ranged from 9 to IOI days (mean $=36 \cdot 4$ ). The patients were followed for periods ranging from 2 to 26 weeks (mean $=9 \cdot 4$ ) (see Table $\mathrm{I}$ ).

No patient suffered a RDC major depressive disorder following injury. Three patients ( 13.6 per cent) experienced a RDC minor depressive disorder after injury which had resolved by the time of the interview. Two patients (9.I per cent) had a RDC minor depressive disorder on initial evaluation. None of the patients developed a major or minor depressive disorder during the follow-up period. Of the 22 patients, five $(\mathbf{2 2 . 7}$ per cent) developed RDC minor depressive disorders following spinal cord injury (see Table I). The time of onset of the five minor depressive disorders ranged from 7 to 30 days (mean 17.6 days). Two patients reported more than mildly depressed affect at the initial interview but did not fulfil the RDC criteria for the diagnosis of a depressive disorder.

Four other diagnoses were applied to patients after their injuries. One patient had a brief delirium following surgery. One patient received a diagnosis of antisocial personality, which also applied to him prior to the injury. Two patients were diagnosed hypomanic after the injury and it was apparent that their hypomania had been present prior to the injury (see Table I).

Six patients received one or more psychiatric diagnoses for the period prior to the injury. These were alcoholism (3), hypomania (2), major depressive disorder (I), antisocial personality (I) and drug abuse disorder (I) (see Table I).

\section{Discussion}

From the initial results of our survey, it appears that depressive disorders, as defined by RDC, affect a minority of patients $(\mathbf{2 2} \cdot 7$ per cent) with traumatic spinal 


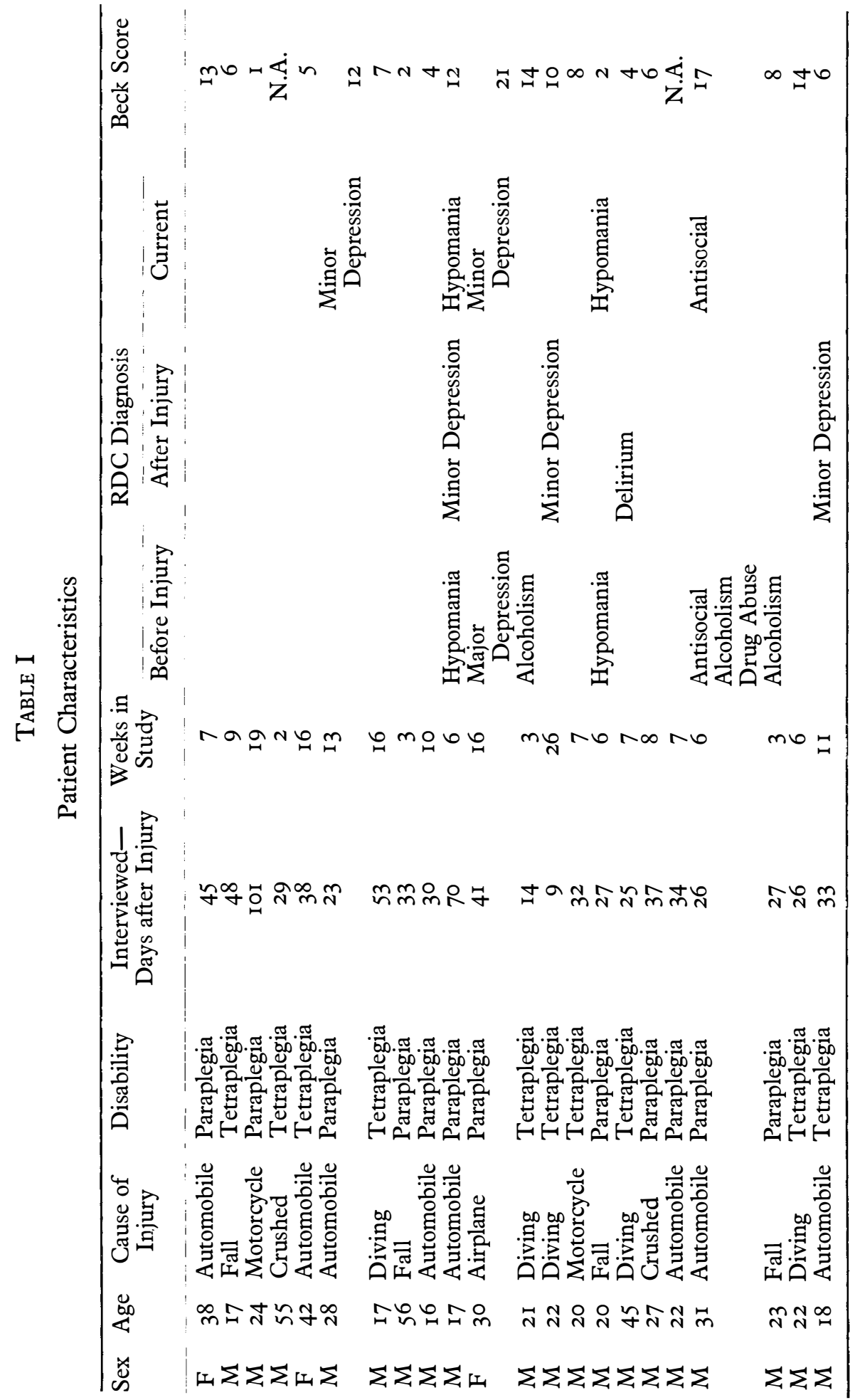


cord injuries within the first few months of injury. This certainly is higher than the 5.7 per cent incidence of major and minor depressive disorders (by RDC criteria) reported in a recent survey of an urban community (Weismann, I978), but it is not as common a sequela to spinal cord injuries as has previously been assumed. It does not appear to be a universal phenomenon and when it does occur, does not appear to be as severe or prolonged as expected.

There are perhaps several reasons for this discrepancy between common clinical wisdom and these findings. While it has been assumed that this patient population is depressed, little work has been done using standardised psychiatric rating instruments to assess whether this was the case (Trieschmann, I980). Confusion or lack of a clear distinction between depressed affect or cognitions and full-fledged depressive disorders may have contributed as well. Perhaps the transient periods of depressed affect manifested by some spinal cord injured patients have been regarded as depressive disorders. In our patients, however, these periods of depressed affect have been brief, mild, non-pervasive, accompanied by few depressive symptoms, and do not satisfy RDC criteria for a diagnosis of depression (major and minor). The assumption that these patients, having suffered a major loss with profound consequences, must or should be depressed may have contributed to an observer bias and led to an overestimation of the incidence of depression.

The outlook for patients with a spinal cord injury has brightened substantially in the last three decades. Medical and surgical care for spinal cord injury and its complications has improved. These patients are less likely to be institutionalised, and reintegration into the community is more feasible and frequent (Trieschmann, 1980). Multidisciplinary team approaches by rehabilitation programmes now pay more attention to the psychological and sexual consequences of spinal cord injuries. The net results of these developments is that a different view of the meaning of spinal cord injury seems to be emerging and with it a different set of expectations on the part of hospital staff, patients, families, and society. Patients today may not be as depressed as patients of the past due to their brighter future and increased opportunity to regain a significant amount of independence.

\section{SUMMARY}

Twenty-two patients with recent spinal cord injuries were evaluated psychiatrically using a standardised interview and diagnostic process. Five patients (22 per cent) were diagnosed as having a depressive disorder. Other mental disorders diagnosed in the sample include hypomania, alcoholism, anti-social personality, drug use disorder and delirium.

\section{RÉSUMÉ}

Vingt-deux patients récement blessés à la moelle épinière ont été évalués d'une manière psychiatrique au moyen d'un procédé d'interview diagnostique. Cinq patients $(22 \%)$ diagnostiqués souffraient d'un désordre de dépression. D'autres désordres trouvés comprennent de l'hypomanie, de l'alcoolisme, du comportement anti-social, de la toxicomanie et du délire.

\section{ZUSAMMENFASSUNG}

Zweiundzwanzig Patienten mit kurz zureckliegenden Reckenmarksverletzungen wurden psychiatrische untersucht und zwar durch Standardinterviews und diagnostische Programme. An fenf (22\%) Patienten wurden depressive Sterungen festgestellt. Folgende andere diagnostizierte geistige Sterungen im genannten Personenkreis lassen sich auffehren: 
Hypomanie, Alkolismus, antisoziale Einstellung, Sterungen durch Drogenkonsum und Delirium.

\section{REFERENCES}

BeCK, A. T., WARD, C. H., MENDELsON, M., et al. (I96I). An inventory for measuring depression. Archives of General Psychiatry, 4, 56I-57I.

Bracken, M. B. \& Shepard, M. J. (I980). Coping and adaption following acute spinal cord injury: A theoretical analysis. Paraplegia, 18, 74-85.

Cook, D. W. (1976). Psychological aspects of spinal cord injury. Rehabilitation Counseling Bulletin, 19, 535-543.

EndicotT, J. \& SPITZER, R. L. (1978). A diagnostic interview: The schedule for affective disorders and schizophrenia. Archives of General Psychiatry, 35, 837-844.

Hohmans, G. (1975). Psychological aspects of treatment and rehabilitation of the spinal cord injured person. Clinical Orthopedics, 112, 8 I-88.

Siller, J. (I969). Psychological situation of the disabled with spinal cord injuries. Rehabilitation Literature, 30, 290-296.

Spitzer, R. L. \& Endicott, J. (1978a). Schedule for Affective Disorders and Schizophrenia, Lifetime Version and Change Version (Third Edition), Biometric Research, New York State Psychiatric Institute, New York.

SPITZER, R. L., ENDICOTT, J. \& RoBINs, E. (I978b). Research Diagnostic Criteria (RDC) for a Selected Group of Functional Disorders (Third Edition). Biometric Research, New York State Psychiatric Institute, New York.

SPITZER, R. L., ENDICOTT, J. \& RoBINS, E. (I978c). Research diagnostic criteria: Rationale and reliability. Archives of General Psychiatry, 35, 773-782.

Stewart, T. D. (1977a). Spinal cord injury: A role for the psychiatrist. American fournal of Psychiatry, 134, 538-54I.

StewART, T. D. (I977b). Coping behavior and the moratorium following spinal cord injury. Paraplegia, 15, 338-342.

Trieschmann, R. B. (1980). Spinal Cord Injuries: Psychological, Social, and Vocational Adjustment. Pergamon Press, New York.

Weismann, M. M., Myers, J. K. \& Harding, P. S. (1978). Psychiatric disorders in a U.S. urban community: 1975-76. American Fournal of Psychiatry, 135, 459-462.

Wittrower, E. D., Gingras, G., Mergler, L., et al. (I954). A combined psychosocial study of spinal cord lesions. Canadian Medical Association fournal, 71, IO9-II5. 